\title{
Human mitochondrial oxidative capacity is acutely impaired following burn trauma
}

\author{
Melanie G. Cree, MD ${ }^{1,5}$, Ricki Y. Fram, MD, MPH ${ }^{2,5}$, David N. Herndon, MD ${ }^{2,5}$, Ting Qian, \\ $\mathrm{MD}^{4}$, Carlos Angel, MD${ }^{2}$, Justin M. Green, $\mathrm{MD}^{2}$, Ronald Mlcak, $\mathrm{PhD}^{5}$, Asle Aarsland, MD, \\ $\mathbf{P h D}^{3,5}$, and Robert R. Wolfe, PhD ${ }^{1,2,5}$ \\ ${ }^{1}$ Dept. of Preventive Medicine and Community Health, The University of Texas Medical Branch, \\ Galveston, TX 77555 \\ ${ }^{2}$ Dept of Surgery, The University of Texas Medical Branch, Galveston, TX 77555 \\ ${ }^{3}$ Dept. of Anesthesiology, The University of Texas Medical Branch, Galveston, TX 77555 \\ ${ }^{4}$ Dept. of Cell Physiology, The University of Texas Medical Branch, Galveston, TX 77555 \\ ${ }^{5}$ Shriners Hospitals for Children, Galveston, TX 77550
}

\begin{abstract}
Background-Mitochondrial proteins and genes are damaged after burn injury in animals but have not previously been assessed in human burn patients.

Methods-The rates of maximal muscle mitochondrial oxidative capacity(ATP production) and uncoupled oxidation(heat production) for both palmitate and pyruvate were measured in muscle biopsies from 40 children sustaining burns $>40 \%$ body surface area and from 13 healthy children controls.
\end{abstract}

Results-Maximal mitochondrial oxidation of pyruvate and palmitate were reduced in burn patients compared to controls $(4.0 \pm 0.2: 1.9 \pm 0.1 \mu \mathrm{molO} 2 /$ citrate synthase activity $/ \mathrm{mg}$ protein $/ \mathrm{min}$ pyruvate; Control:Burn; $\mathrm{P}<0.001$ and 3.0 $\pm 0.1: 0.9 \pm 0.03 \mu \mathrm{molO} 2 /$ citrate synthase activity $/ \mathrm{mg}$ protein/min palmatyl CoA; Control:Burn; $\mathrm{P}=0.003)$. Uncoupled oxidation was the same between groups.

Conclusions-The maximal coupled mitochondrial oxidative capacity is severely impaired after burn injury, although there are no alterations in the rate of uncoupled oxidative capacity. It may be that the ratio of these indicates that a larger portion of energy production in trauma patients is wasted through uncoupling, rather than used for healing.

\section{Keywords}

Trauma; burn; mitochondria; muscle

\footnotetext{
(C) 2008 Excerpta Medica, Inc. All rights reserved.

Address correspondence to: Robert R. Wolfe, Ph.D., DWR Institute on Aging, 4301 W. Markham St Slot 806, Little Rock, AR 72205, Phone: 501-526-5708, Fax: 501-526-5710, Email: rwolfe2@uams.edu.

Publisher's Disclaimer: This is a PDF file of an unedited manuscript that has been accepted for publication. As a service to our customers we are providing this early version of the manuscript. The manuscript will undergo copyediting, typesetting, and review of the resulting proof before it is published in its final citable form. Please note that during the production process errors may be discovered which could affect the content, and all legal disclaimers that apply to the journal pertain.
} 


\section{Introduction}

Serious injury, including burn trauma, induces a hyper metabolic response that despite over 100 years of study is still not well understood. The occurrence of increased metabolic rate and hyperglycemia post-trauma is well documented(1-3). Hyperglycemia can be attributed to both increased glucose production and peripheral insulin resistance (3). The increased metabolic rate may be due to increased energy demands for advanced immune response, tissue healing and in the case of burns, maintenance of body temperature after loss of the skin barrier (4-6). Advances in burn care that include maintaining patient room temperatures above $30^{\circ} \mathrm{C}$, applying occlusive dressings and the use of antibiotics have decreased both the energy requirements and the morbidity in burned patients (4). However, whereas the extent of elevation of the resting energy expenditure has decreased from the range of 160-200\% to around $130 \%$ of expected from unburned individuals, the hyper-metabolic response persists in burned patients maintained in a warm environment (4).

The ability of mitochondria to utilize glucose and fat for ATP production through coupled oxidation may be related to the hyper metabolic response post-injury. Several studies of burned rats and dogs have shown decreased tissue concentrations of ATP post-burn $(7,8)$. More recent studies in burned animals have found decreased maximal mitochondrial oxidative capacity in skeletal muscle, liver and cardiac muscle compared to non-burned animals (9-12). The typical burn hyper-metabolic response was present in all of these animals. Deceased surgical patients had irregular hepatic mitochondria(13). These studies indicate that severe injury is associated with decreased ATP concentrations and impaired mitochondrial function, and that moderate surgical trauma induces changes great enough to be seen with histology in the liver.

Mitochondrial function has not previously been assessed in human burn patients. Thus, this study was designed to compare the mitochondrial glucose and fat oxidation rates in muscle tissue from previously healthy burned children, with those in healthy children.

\section{Methods}

This was a prospective, cross sectional study with a patient and a control group. All protocols were approved by the IRB at the University of Texas Medical Branch. A legal guardian provided permission for participation of the child in the study. Assent was obtained in children aged 0-17 when medically and ethically possible.

\section{Patient study}

Children aged 0-17 with $>40 \%$ total body surface area burns that would require skin grafting, who arrived at our hospital within 96 hours of injury were eligible. Children with major electrical burns, renal or hepatic failure, severe sepsis or who had required resuscitation from cardiac arrest were excluded. 40 children were enrolled consecutively over a period of 30 months. Medical care was determined by faculty surgeons, fellows and residents according to clinical protocols that have been previously described (14). Patients were fed with Vivonex T.E.N. ( ) (Novartis, Minneapolis, Minnesota $-82 \%$ carbohydrate, $15 \%$ protein, $3 \%$ fat) at 1.4 times their measured resting energy expenditure. The fasted resting metabolic rate was determined once a week in the early morning at $30^{\circ} \mathrm{C}$ with a Vmax 29 metabolic cart (Sensormedics, Yorba Linda, CA).

A muscle biopsy and a 4 hour hyperinsulinemic-euglycemic clamp, preceded by an 8 hour fast were performed within 10 days of injury, 4 days after the children's first debridement and skin grafting operation. We chose this time point because of the relative standardization of treatment for the previous 5 days, and since it did not reflect initial resuscitative efforts, 
which can vary greatly. During the clamp, insulin was infused at a rate of $1.5 \mathrm{mU} \bullet$ $\mathrm{kg}^{-1} \cdot \mathrm{min}^{-1}$ into a central vein and $20 \%$ dextrose was simultaneously infused to maintain a plasma glucose concentration between $80-90 \mathrm{mg} / \mathrm{dL}$. Insulin sensitivity is presented as $\mathrm{mg}$ glucose infused $/ \mathrm{kg} / \mathrm{min}$.

\section{Control Study}

Children undergoing open abdominal surgeries for non-metabolic illness such as hernia repair, orchiplexy, or ureter reimplantation were chosen as our control population. A small piece of the rectus abdominus or external oblique muscle was removed from the margin of the site of the surgical incision site for mitochondrial oxidation analysis.

13 children served as controls. One child had a parent with type 2 diabetes, and four additional children had a grandparent with type 2 diabetes. None of the mothers of the children had gestational diabetes during pregnancy. All of the children were lean and had no clinical signs of diabetes, such as polyuria, polydypsia or acanthosis nigricans.

\section{Analysis Methods}

Plasma glucose concentration was measured on an YSI 2300 Stat glucose/lactate analyzer (YSI, Inc. Yellow Springs, OH). Serum insulin concentrations were measured using radioactive immuno assay (Diagnostic Laboratories, Los Angeles, CA). Blood pH was measured with a Bayer Rapid Point 400 Blood Gas analyzer (Holliston, MA). Blood urea nitrogen and liver enzymes were measured on a Dade Behring Dimension Xpand Chemistry analyzer (Deerfield, Il). Plasma cortisol was measured by ELISA on a Bayer Advia Centaur (Holliston, MA)

Maximal mitochondrial oxidation of pyruvate and mitochondrial respiratory rates were measured in fresh muscle tissue as previously described $(15,16)$. Briefly, tissue was washed and minced into small pieces in a relaxing solution, the incubated in a saponin solution to permeabilize the sarcolemma membrane. Glucose oxidation was measured with $2 \mathrm{mM}$ of malate and $10 \mathrm{mM}$ of pyruvate as substrate and $0,5 \mathrm{mM}$ of ADP. For the measurement of FFA oxidation, $1 \mathrm{mM}$ of palmitoyl-L-carnitine was sued rather than pyruvate. All measurements were conducted with a Clark-type electrode (Hansatech, Norfolk, UK) in a water jacketed chamber at $30^{\circ} \mathrm{C}$. These measurements are termed "maximal" as there is no limitation of substrate or necessary co-factors, and thus the only limitation in oxidation is from the mitochondria themselves. Following these measurements, the samples were weighed, and the citrate synthase activity and protein contents were measured, in order to normalize the results for mitochondrial content $(17,18)$.

\section{Results}

Demographics from both groups are shown in Table 1. The two groups were similar with respect to age, gender and race. The physiologic measurements from the burn patients taken on the day of biopsy are shown in table 2. As indicated by the increased heart rates, respiratory rates and predicted resting energy expenditure, the children with burns were hyper-metabolic. Further, fasting glucose concentrations were elevated, and insulin stimulated glucose uptake was depressed.

The results of the mitochondrial function tests are shown in figure 1. The state 3 maximal mitochondrial oxidative capacity of pyruvate, representing coupled oxidation for ATP production, was significantly $(\mathrm{P}<0.001)$ decreased by $50 \%$ in burned patients compared to healthy controls (Figure 1a). The state 3 maximal palmitate oxidative capacity was reduced by $66 \%$. The rate of state 4 , or uncoupled oxidation of both pyruvate and palmitate was equal between the burned and the healthy groups (Figure 1b). The respiratory control ratio, 
or the ratio of state 3 to state 4 oxidation is shown in figure $1 \mathrm{c}$. This ratio represents substrate oxidation coupled to ADP use compared to the rate of uncoupled oxidation. Due to the increased state 3 oxidation in the healthy children, the respiratory control ratio was significantly greater $(\mathrm{P}<0.001)$ in healthy children for both palmitate and pyruvate compared to burned children.

\section{Discussion}

This is the first time that mitochondrial function has been measured in human tissue from burned patients, as well as from normal children. The findings of reduced ATP production following burn were not unanticipated. Previous studies in burned animals have shown a decreased production ATP following injury. Burned mice had a 43\% decrease in ATP production compared to control animals 3 days after injury, associated with decreased mitochondrial protein gene expression (9). Another study in animals found that burn traumainduced alteration in the skeletal muscle mitochondrial membrane within 15 min following the trauma (11). ATP production was reduced by $87 \%$ in cardiac myocytes from burned rats 24 hours after injury(10). Further, the respiratory control ratio in burned dogs was half of that seen in control animals(8). Thus, our findings are similar to what has been previously demonstrated in animal models.

Both mitochondrial pyruvate and palmitate oxidation were reduced. Whereas a limitation of fatty acid oxidation could have occurred because of limited transport of long-chain fatty acids into the mitochondria through carnitine palmitate transferase-1, this could not explain the simultaneous drop in pyruvate oxidative capacity. Since both the maximal mitochondrial oxidative capacity of pyruvate and palmitate were decreased, there may be a dysfunction in a process which is common to both. The metabolism of these two substrates converges at the level of acetyl CoA, prior to entry into the citric acid cycle and then subsequent oxidative respiration (Figure 2). Both citrate synthase and cytochrome C- oxidase have important roles in the generation of ATP(19). Citrate synthase is the first enzyme in the citric acid cycle, and cytochrome $\mathrm{C}$ is active in the electron transport chain, between complex III and IV. These two enzymes are thus commonly examined when trying to better understand mitochondrial dysfunction, and both have been found to be decreased in animals following burn injury(10). However, if the defect in oxidation was solely at the level of the citric acid cycle, then one would expect that this would affect the rate of coupled and uncoupled oxidation equally, as the overall supply of substrate to the respiratory chain would be reduced. Thus, it is likely that burn induced a change within the respiratory chain of the mitochondria.

Whereas the rate of ATP production is decreased in almost all models of burn, maximal mitochondrial oxidative capacity may not be the most important finding. Previous in-vivo studies in burned patients have found that despite the increased metabolic turnover of pyruvate, the pyruvate oxidation rate is still below the maximum(20). Further, while lactate levels are increased, so is the turnover of the citric acid cycle, so that the increased lactate does not indicate that there is a deficiency in the citric acid cycle compared to the initial steps of glycolysis, but rather that the entire pathway is up-regulated. Consistent with this interpretation, stimulation of pyruvate dehydrogenase with dichloroacetate increased pyruvate oxidation in burned children, which could only have occurred if the citric acid cycle enzymes were not rate limiting(21). This is in contrast to studies of enzyme levels that indicate that citric acid cycle enzymes are decreased, yet enzyme concentrations may not accurately reflect the overall turnover of the citric acid cycle. Additionally, despite the effects of a large burn injury, when studied patients are at rest in bed, they have the ability to arise and ambulate, thereby increasing their rate of substrate oxidation significantly above the resting level. Thus the measured values in this paper do not reflect the maximal oxidative capacity in vivo. 
Increased oxidative phosphorylation uncoupled from ATP production, as seen in state 4 respiration, has been proposed to contribute to morbidity and mortality in burn patients, and is estimated to account for approximately $40 \%$ of the hyper-metabolic response seen after burn trauma(22). Uncoupling proteins 1 and 2 are proton transporters within the inner mitochondrial membrane and have primarily been linked to increased thermogenesis through increased proton leak (23). Increasing the temperature of burn patients rooms, thus decreasing the need for uncoupled oxidation, improved mortality significantly (4). While we did not observe an increase in the rate of state 4 oxidation per se in the burn patients compared to the healthy controls, it may be the ratio of the coupled to the uncoupled oxidation that is more related to the energy requirements in burn patients.

An association between decreased mitochondrial function and insulin resistance has been shown in several circumstances, including type 2 diabetes and aging $(24,25)$. The burned children had reduced insulin stimulated glucose uptake when compared to similar hyperinsulinemic-euglycemic clamps in healthy children (26). This work demonstrates yet another model in which insulin resistance may be related to mitochondrial function. It could be that the increases in proton release relative to ATP generation, primarily through uncoupling protein-1, lead to increased reactive oxygen species, and damage to lipid products. The relation between decreased state 3 oxidation and/or increased state 4 oxidation with a decreased state 3/state 4 ratio and increased protein oxidation has been demonstrated in several models $(27,28)$. It is theorized that the increased protons can trigger increases in tumor necrosis alpha, which in turn can inhibit insulin signaling through protein kinase $\mathrm{C}$ $(29,30)$.

In conclusion, muscle mitochondrial function is significantly decreased in burn patients compared to healthy controls. The oxidative capacity of both pyruvate and fat in the mitochondria was reduced by more than $50 \%$ one week following burn, while the capacity for uncoupled oxidation was maintained. These changes were seen in concomitantly with decreased insulin sensitivity.

\section{Acknowledgments}

Funding Sources:
Shriners Hospital Grant 8490 to Robert R. Wolfe;
NIH R01 DK041317 "Substrate Cycling in Burns” to Robert R. Wolfe;
NIH R01-GM56687 "Modulation of the Postburn Hypermetabolic Response” to D.N. Herndon.

\section{References}

1. Howard JM. Studies of the absorption and metabolism of glucose following injury; the systemic response to injury. Ann Surg. 1955; 141(3):321-326. [PubMed: 14350571]

2. Frayn KN. Effects of burn injury on insulin secretion and on sensitivity to insulin in the rat in vivo. Eur J Clin Invest. 1975; 5(4):331-337. [PubMed: 1175672]

3. Wolfe RR. Glucose metabolism in burn injury: a review. J Burn Care Rehabil. 1985; 6(5):408-418. [PubMed: 3916430]

4. Wilmore DW, Long JM, Mason AD Jr, Skreen RW, Pruitt BA Jr. Catecholamines: mediator of the hypermetabolic response to thermal injury. Ann Surg. 1974; 180(4):653-669. [PubMed: 4412350]

5. Wolfe RR, Herndon DN, Jahoor F, Miyoshi H, Wolfe M. Effect of severe burn injury on substrate cycling by glucose and fatty acids. N Engl J Med. 1987; 317(7):403-408. [PubMed: 3614284]

6. Wolfe RR, Klein S, Herndon DN, Jahoor F. Substrate cycling in thermogenesis and amplification of net substrate flux in human volunteers and burned patients. J Trauma. 1990; 30(12 Suppl):S6-S9.

[PubMed: 2254993] 
7. Gore DC, Rinehart A, Asimakis G. Temporal changes in cellular energy following burn injury. 2005; 31(8):998-1002.

8. Huang YS, Yang ZC, Liu XS, et al. Serial experimental and clinical studies on the pathogenesis of multiple organ dysfunction syndrome (MODS) in severe burns. 1998; 24(8):706-716.

9. Padfield KE, Astrakas LG, Zhang Q, et al. Burn injury causes mitochondrial dysfunction in skeletal muscle. Proc Natl Acad Sci U S A. 2005; 102(15):5368-5373. [PubMed: 15809440]

10. Liang WY, Tang LX, Yang ZC, Huang YS. Calcium induced the damage of myocardial mitochondrial respiratory function in the early stage after severe burns. Burns. 2002; 28(2):143146. [PubMed: 11900937]

11. Yasuhara S, Perez ME, Kanakubo E, et al. Skeletal muscle apoptosis after burns is associated with activation of proapoptotic signals. Am J Physiol Endocrinol Metab. 2000; 279(5):E1114-E1121. [PubMed: 11052967]

12. Wang XM, Chen KM, Wang Y, Shi SP. Functional changes in rat-liver mitochondria during the early phase of burn injury. Burns Incl Therm Inj. 1986; 12(7):461-464. [PubMed: 3779466]

13. Vanhorebeek I, De Vos R, Mesotten D, Wouters PJ, De Wolf-Peeters C, Van den Berghe G. Protection of hepatocyte mitochondrial ultrastructure and function by strict blood glucose control with insulin in critically ill patients. Lancet. 2005; 365(9453):53-59. [PubMed: 15639679]

14. Pereira C, Murphy K, Jeschke M, Herndon DN. Post burn muscle wasting and the effects of treatments. Int J Biochem Cell Biol. 2005; 37(10):1948-1961. [PubMed: 16109499]

15. Chance B, Williams GR. The respiratory chain and oxidative phosphorylation. Adv Enzymol Relat Subj Biochem. 1956; 17:65-134. [PubMed: 13313307]

16. Veksler VI, Kuznetsov AV, Sharov VG, Kapelko VI, Saks VA. Mitochondrial respiratory parameters in cardiac tissue: a novel method of assessment by using saponin-skinned fibers. Biochim Biophys Acta. 1987; 892(2):191-196. [PubMed: 3593705]

17. Alp PR, Newsholme EA, Zammit VA. Activities of citrate synthase and NAD+-linked and NADP +-linked isocitrate dehydrogenase in muscle from vertebrates and invertebrates. Biochem J. 1976; 154(3):689-700. [PubMed: 8036]

18. Lowry OH, Rosebrough NJ, Farr AL, Randall RJ. Protein measurement with the Folin phenol reagent. J Biol Chem. 1951; 193(1):265-275. [PubMed: 14907713]

19. Champe, P.; Harvey, R. Lippincott's Illustrated Reviews. 2nd ed.. Philadelphia: Lippincott Willians and Wilkins; 1994.

20. Wolfe RR, Jahoor F, Herndon DN, Miyoshi H. Isotopic evaluation of the metabolism of pyruvate and related substrates in normal adult volunteers and severely burned children: effect of dichloroacetate and glucose infusion. Surgery. 1991; 110(1):54-67. [PubMed: 1866694]

21. Ferrando AA, Chinkes DL, Wolf SE, Matin S, Herndon DN, Wolfe RR. Acute dichloroacetate administration increases skeletal muscle free glutamine concentrations after burn injury. Ann Surg. 1998; 228(2):249-256. [PubMed: 9712571]

22. Yu YM, Tompkins RG, Ryan CM, Young VR. The metabolic basis of the increase of the increase in energy expenditure in severely burned patients. JPEN J Parenter Enteral Nutr. 1999; 23(3):160 168. [PubMed: 10338224]

23. Nubel T, Ricquier D. Respiration under control of uncoupling proteins: Clinical perspective. Horm Res. 2006; 65(6):300-310. [PubMed: 16641553]

24. Kelley DE, He J, Menshikova EV, Ritov VB. Dysfunction of mitochondria in human skeletal muscle in type 2 diabetes. Diabetes. 2002; 51(10):2944-2950. [PubMed: 12351431]

25. Petersen KF, Befroy D, Dufour S, et al. Mitochondrial dysfunction in the elderly: possible role in insulin resistance. Science. 2003; 300(5622):1140-1142. [PubMed: 12750520]

26. Veening MA, Van Weissenbruch MM, Delemarre-Van De Waal HA. Glucose tolerance, insulin sensitivity, and insulin secretion in children born small for gestational age. J Clin Endocrinol Metab. 2002; 87(10):4657-4661. [PubMed: 12364453]

27. Magalhaes J, Ascensao A, Soares JM, et al. Acute and severe hypobaric hypoxia increases oxidative stress and impairs mitochondrial function in mouse skeletal muscle. J Appl Physiol. 2005; 99(4):1247-1253. [PubMed: 15905323] 
28. Oliveira CP, Coelho AM, Barbeiro HV, et al. Liver mitochondrial dysfunction and oxidative stress in the pathogenesis of experimental nonalcoholic fatty liver disease. Braz J Med Biol Res. 2006; 39(2):189-194. [PubMed: 16470305]

29. Kim JK, Fillmore JJ, Sunshine MJ, et al. PKC-theta knockout mice are protected from fat-induced insulin resistance. J Clin Invest. 2004; 114(6):823-827. [PubMed: 15372106]

30. Li YP, Atkins CM, Sweatt JD, Reid MB. Mitochondria mediate tumor necrosis factor-alpha/NFkappaB signaling in skeletal muscle myotubes. Antioxid Redox Signal. 1999; 1(1):97-104. [PubMed: 11225736] 


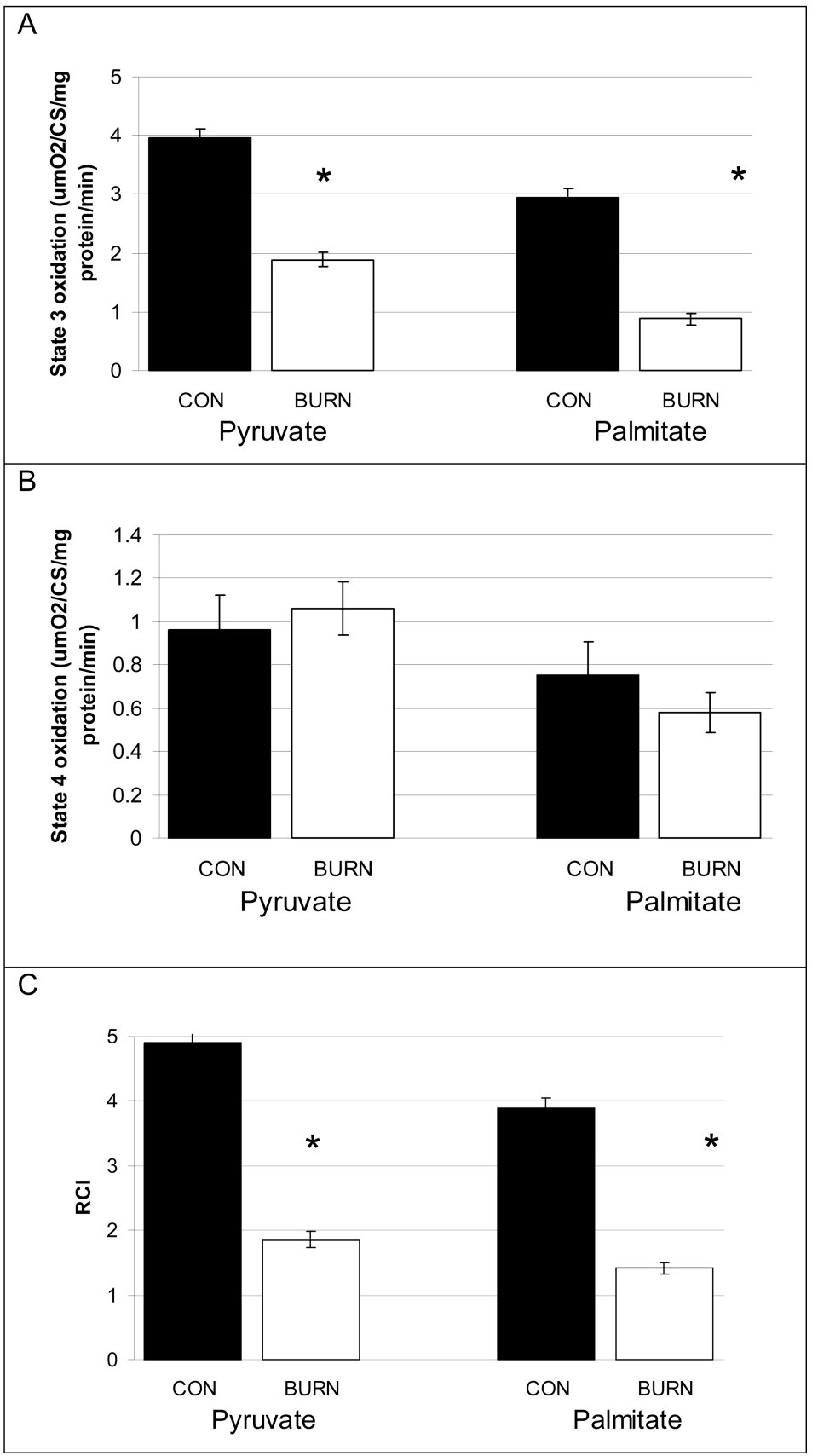

Figure 1. Coupled and uncoupled maximal mitochondrial function and the ratio of coupled to uncouple mitochondrial function

(A) Maximal mitochondrial state 3 oxidative respiration (ATP production) from pyruvate and palmitate. The coupled oxidation was significantly higher in healthy children $(\mathrm{P}<0.001)$

(B) Uncoupled mitochondrial oxidation from pyruvate and palmitate. There was no difference between the groups.

(C)The efficiency of mitochondrial ATP production relative to uncoupled heat production from pyruvate and palmitate. The ratio of ATP production to uncoupled respiration was significantly greater in healthy children $(\mathrm{P}<0.001)$ 


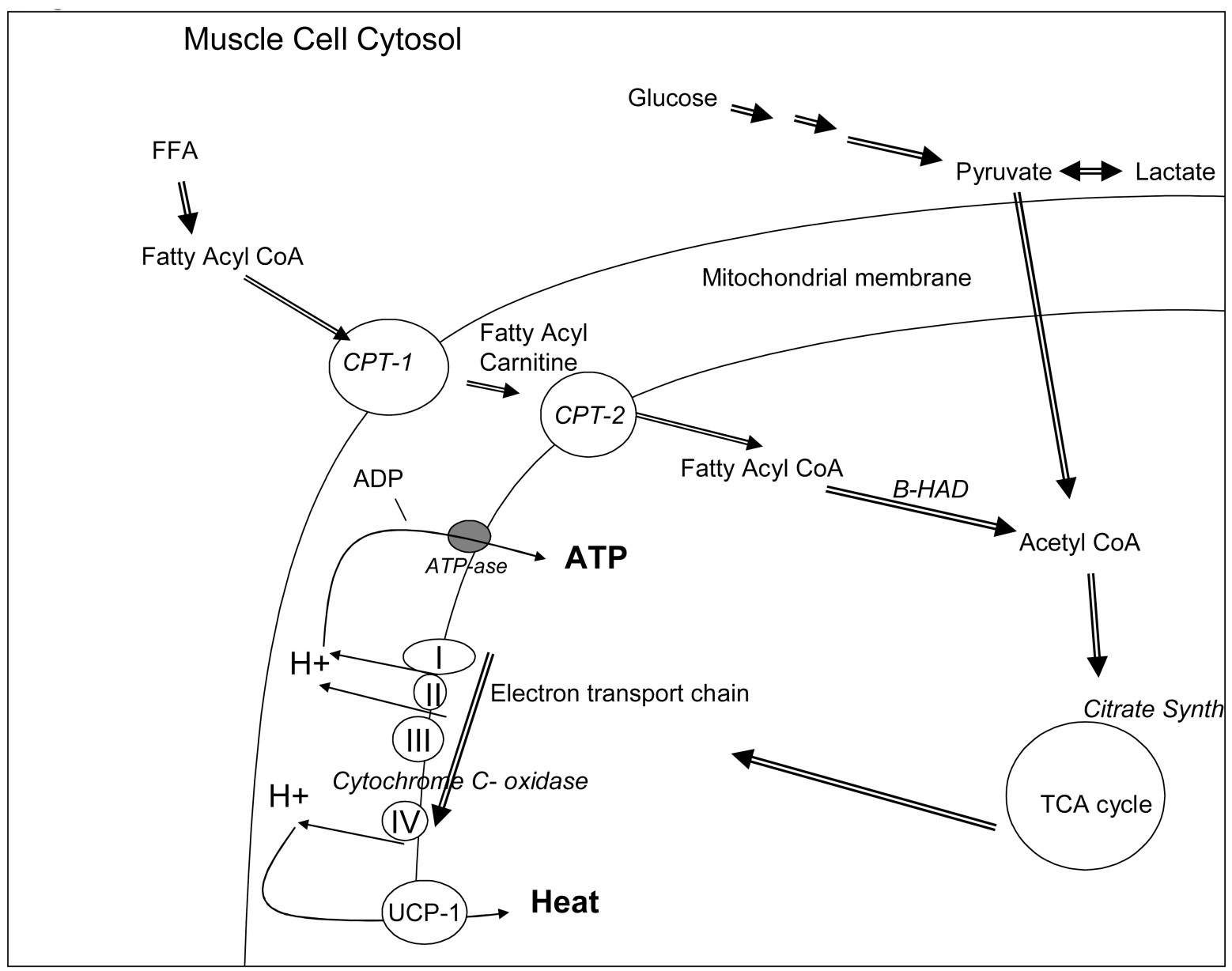

Figure 2. Pathway of production of ATP from both glucose and free fatty acids

A representation of a muscle cell is shown. Glucose and FFA are broken down in the cytosol to pyruvate and fatty acyl CoA, respectively. Pyruvate can then cross the mitochondrial membranes, and is converted to acyl CoA via pyruvate dehydrogenase. Fatty Acyl CoA is transferred across the outer mitochondrial membrane via carnitine palmatyl transferase- 1 (CPT-1) and becomes fatty acyl carnitine that is then transferred across CPT-2 and return to fatty acyl CoA. Fatty acyl CoA is a substrate for $\beta-H A D$, which breaks off acyl groups to form acetyl CoA. Acetyl CoA enters the tricarboxcylic acid cycle (TCA) and produces multiple metabolites which enter the electron transport chain of 4 key cytochromes to form protons. The protons are then used by ATP-ase to charge ADP into ATP via coupled respiration, or are transferred by uncoupling protein -1 to produce heat, via uncoupled oxidation. 


\section{Demographics}

\section{Table 1}

Demographic data of study participants

\begin{tabular}{ccc|}
\hline Demographics & Patients & Controls \\
Number & 40 & 13 \\
Age (Years) & $7 \pm 1$ & $8 \pm 2$ \\
Male/female & $33 / 7$ & $9 / 3$ \\
Total TBSA & $65 \pm 2$ & - \\
$\mathbf{3}^{\text {rd degree TBSA }}$ & $56 \pm 4$ & - \\
Race (H/W/B) & $32 / 7 / 1$ & $4 / 6 / 3$ \\
\hline
\end{tabular}


Table 2

Physiological measurements on the day of biopsy in burned patients

Clinical measurements from the day of biopsy. Data are Means \pm SEM.

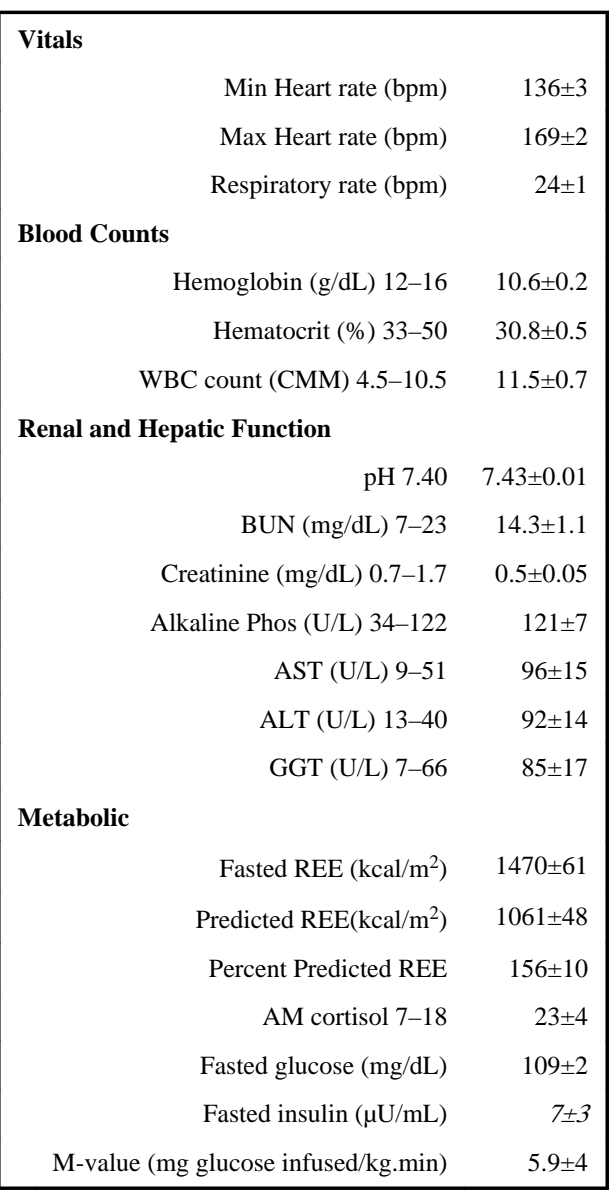

